\title{
Research on the Application of Virtual reality Technology in Manchu Architecture Protection
}

\author{
Jian Xiao ${ }^{1 *}$, TengFei zhou ${ }^{1}$, SiYu Guo ${ }^{1}$
}

\author{
${ }^{I}$ Dalian Polytechnic University \\ ${ }^{*}$ Corresponding author. Email: 497524298@qq.com
}

\begin{abstract}
With the internal development and practice of digital technology in the research on inheritance, protection and innovation of intangible cultural heritage, virtual reality technology, as an advanced and important presentation form, has been applied to the protection practice. Combined with the living characteristics of intangible cultural heritage, this paper explores the application of virtual reality technology in intangible cultural heritage protection, and builds a virtual reality display platform to improve the recognition, sense of scene and interaction. Meanwhile, exploring new ideas for intangible cultural heritage protection and innovation in the post-epidemic era.
\end{abstract}

Key words: Virtual reality, Manchu, Architecture, Protection

\section{INTRODUCTION}

Virtual reality technology, also known as spiritual technology, a new digital presentation technology developed in the twentieth century, which combines computer, electronic information, simulation model. The basic working principle is the establishment of virtual simulation scenes to the user's immersive deep immersion, in terms of visual, auditory or even tactile, smell, etc. using a virtual digital environment that is highly similar to the real environment in terms of smell, $3 \mathrm{D}$ glasses ${ }^{[1]}$, helmets and other equipment are used to interact with the digital objects in the virtual simulation environment.And the interactive method is used to complete the relevant experimental operation, process browsing and work display.

Intangible cultural heritage records the history and changes of Chinese traditional culture. It is a living fossil of regional economy, culture and politics. It is an indispensable part of the treasure house of Chinese cultural information. Using big data to build a digital platform for intangible cultural heritage collection, storage and sharing of relevant data resources are the prerequisites for the involvement of virtualreality technology in intangible cultural heritage management. According to the resource characteristics of intangible cultural heritage, a big data platform based on data census resources, project classification resources, thematic design resources and public resources can be constructed, so as to ensure the richness and integrity of the intangible cultural heritage data platform. On the premise of fully meeting the requirements of information access and data browsing, it can also improve the utilization of professional data of intangible cultural heritage.

Manchu is an important part of the Chinese nation, mainly distributed in Northeast and North China. With the continuous development and changes of society and natural environment, Manchu traditional culture needs to be protected urgently. In recent years, the state has attached great importance to the protection of traditional culture, and the people have begun to realize the importance of national cultural protection and inheritance. The protection of some Manchu folk houses, songs, dances, customs and other cultural heritage is being carried out in an orderly manner. Up to now, the Manchu nationality has applied for 2 United Nations cultural heritage protection projects, 7 national cultural heritage protection projects and hundreds of provincial cultural heritage protection projects. These protection projects cover many fields such as ethnic songs and dances, customs, handicrafts and architecture, and effectively consolidate the foundation for the protection of Manchu traditional culture.

\section{DIGITAL PROTECTION OF MANCHU TRADITIONAL ARCHITECTURE}

The Manchu traditional architecture has various types and rich shapes. It contains the profound Manchu 
national culture and rich wisdom. It provides valuable material materials for people to understand the development process of Manchu traditional culture, national spiritual form, production and life style and customs. It is also the symbol and carrier of the essence of national culture. If effective protection measures are not taken, It will gradually disappear, which will be a huge loss to the development history of social civilization. In addition, limited by objective conditions, the protection methods of some intangible cultural heritage are relatively conservative and backward. Although the original appearance of intangible cultural heritage is retained, it is lack of publicity and inheritance, which makes intangible cultural heritage lose its vitality. In view of this, we must pay attention to and start the protection of Manchu traditional folk houses.

The full number of Manchu traditional buildings is wide and distributed, and is an important part of Manchu cultural heritage. In this paper, the digital technology is the entry point, and the virtual simulation technology is involved in intangible cultural heritage protection and innovative research. Through the technical means of image acquisition digitization, three-dimensional scanning digitization, model establishment digitization, information system digitization, virtual reality digitization and so on, it could more effectively protect the traditional Manchu architecture ${ }^{[2]}$. The application of virtual simulation technology to the research on the protection, inheritance and innovation of Manchu traditional buildings can assist the mobile terminal as the equipment medium for information transmission, improve the display rate of traditional buildings, make the remote traditional buildings show to the audience in holographic image without the restriction of region, distance and climate conditions, and let the audience in the virtual simulation environment of Manchu settlements. The restrictions of climatic conditions are presented to audience groups, allowing viewers to surveyed in the Manchu gathered virtual simulation environment, from the truly entered the village, from the traditional passive understanding to active exploration, create a personalized interaction process, and let people obtain and master richer and more interesting intangible cultural heritage information.

The original model acquisition method often adopts mold turning or sculpture, but since the target itself has certain destructiveness, it will lead to a decline in the real degree of the model. In order to maintain a high degree of consistency with real target buildings, the method of establishing a three-dimensional scanning digital model is generally employed.

According to the survey, the protection of world intangible cultural heritage has been dominated by traditional methods for a long time. It usually uses paper documents, photos and other methods to preserve relevant resources. This form often causes material damage and irreparable loss over time, natural and man-made disasters and other situations. As the modern technology in most areas where many intangible cultural heritages are located is generally relatively backward, and their protection concepts and means are relatively old, the development of intangible cultural heritage protection is relatively slow. In addition, the intangible cultural heritage inheritors have great limitations in their understanding and mastery of digital technology, and sometimes only focus on traditional technical means and ignore the application value of modern digital technology. However, some digital protection work has been carried out in many areas, there are some problems such as incomplete registration information and low data accuracy due to technical constraints. At the same time, the integration of digital technology into intangible cultural heritage protection requires a certain amount of financial support in software $R \& D$ and hardware procurement. However, many intangible cultural heritage have a small audience and do not have an advantage in talent training and financial support, so it is difficult to provide substantive help for inheritance protection and innovative development. Therefore, it has been very difficult to really introduce digital technology into intangible cultural heritage. ${ }^{[3]}$

\section{CHARACTERISTICS OF LIAONING MANCHU NATIONALITY INTANGIBLE CULTURAL HERITAGE}

As an advanced information technology means, multimedia integrates a variety of information processing technologies such as audio, video, image and text. It can receive and process information in different formats. After processing with computer technology, it can output information in rich formats and ways, which can meet the needs of people to obtain and apply different information. Multimedia technology is a comprehensive concept. Its information content is very complex and diverse. Its information processing objects do not exist independently, but are inextricably linked in time and space. In addition, multimedia technology has the characteristics of diversification, integration and interaction. It can be widely used in various fields of social life and bring rich and colorful information to people. In the process of protecting and inheriting the traditional culture of ethnic minorities, we can give full play to the great advantages and role of multimedia technology.

Manchu precious cultural heritage is divided into people in the people of Manchu, which is to meet the accumulation of people in long-term production and life practice. Through different technical means, the fragmented intangible cultural heritage has become a standardized data that could be fully utilized, and the information sharing can be achieved by digital technology, and the intangible cultural heritage is 
presented in front of the audience. It is possible to maximize the protection of traditional national cultural art.

The architectural form of Manchu inhabited areas is based on the local natural climate and environmental conditions, fully absorbs the national history, culture, customs, beliefs and other factors, and creates an architectural form with the essence of traditional national residential culture after the verification of practical life. This is an active form, which can fully coordinate and unify the architectural state with the natural environment from the perspective of respecting nature, and fully meet the aesthetic consciousness and ethical spirit of different ethnic groups. In the long-term development process, the architectural form of Manchu nationality has gradually changed by absorbing the architectural art forms of other nationalities. It is interactive and integrated in architectural structure, pattern style and colour. At the same time, Manchu architecture retains the essence of typical traditional architectural culture unique to its own nation and region to the greatest extent.Thus, an artistic expression form with strong Manchu architectural structure and decorative style has been formed, which can fully meet the actual needs of national life and have the use value of national architectural cultural heritage ${ }^{[4]}$.

Manchu early traditional architecture generally used local materials, and the soil, masonry, grass and trees as the main materials. The walls of Manchu buildings were mostly rammed earth for short, the roof was paved with Mao grass and the living room is relatively broad and looks like an open pocket. It is also called "pocket room" in architectural research. At the same time, due to the low temperature in winter, the Manchu buildings are equipped with heated Kang to resist the severe cold climate. The heated Kang is often called "Wanzi Kang". It is built with adobe, and a flue is reserved around the indoor room to burn fire for heating. This is not only a unique architectural structure of Manchu architecture, but also an intelligent product of life experience accumulated in the local bad environment. At the same time, the chimney forexhaust smoke is located about one meter away from both sides of the gable. The Manchu lives in the construction of the brick wall, which is replaced by the wooden fence. The early Manchu architectural level was relatively backward, and its spatial pattern was relatively simple.

\section{THOUGHTS ON THE PROTECTION AND INHERITANCE OF MANCHU TRADITIONAL ARCHITECTURE}

The Manchu also has its own exclusive religious beliefs, and the hierarchical colour of the whole nation is very strong. Therefore, the design of houses has obvious heterogeneity in area, scale and so on. Most Manchu autonomous counties and townships in China are located in rural areas. Under the influence of long-term history and the limitations of nature, Manchu architecture has also undergone some changes, including the consideration of the material field, but also the pursuit of the spiritual level. Such a very unique spatial presentation also shows a very strong national flavor to a certain extent. The high integration of architecture and external environment also fully reflects the creativity and innovation of the majority of Manchu people. This is also a presentation and expression of Manchu culture, and an expression of the high integration of nature and humanities. In the design process of architectural design and living space, it is introduced into a cultural element, making it a rich national style, and is one of the important Manchu culture symbols. The analysis and treatment of architectural elements are also gradually developing in the direction of innovation. In this way, a lot of Manchu elements and Manchu culture are integrated into the architectural field, which creates a better environmental atmosphere for the deep display of architectural Manchu atmosphere. It is an important way to innovate rural planning practice and expand the vitality of Manchu culture. At the same time, it improves the influence of Manchu culture and creates an all-round expansion of Manchu cultural tourism development, which also makes further supplements of architectural art of Manchu characteristics to traditional Chinese decorative culture.

To repair the old as the old, for the rescue protection of Manchu characteristic building communities, learning from advanced protection means and technical concepts, evaluating the overall value of the building communities that have not been demolished and have high repair and protection value, putting forward reasonable measures, setting repair schemes and carrying out the rescue protection. In the repair plan, we will force the old cultural relics protection concept, refuse artificial scenery and refuse to demolish the new construction. At the same time, buildings that have no protection significance and will endanger other protected areas shall be demolished as soon as possible. Generally speaking, making full use of nature and giving full play to the function of nature is the core element of traditional architecture. But in practice, many traditional buildings that meet the needs of residents are preserved and presented with residential life as the main carrier ${ }^{[5]}$.

\section{CONCLUSION}

The establishment of standards plays an important role in the digital construction of virtual simulation of intangible cultural heritage. Because in the process of building various digital information platforms, if there are non-uniform operation standards and non-standard data collection, it will seriously affect the accuracy of digital information of intangible cultural heritage, and cannot fundamentally establish a database consistent with the actual situation of intangible cultural heritage, and unable to truly give full play to the practical value of 
digital technology. It will even lead to the failure of the digital protection of intangible cultural heritage. For the establishment of intangible cultural heritage digitization standards, we can learn from the mature information database construction standards and establish relatively unified operation specifications for data collection, information storage and resource management, so as to provide a stable foundation for the establishment of intangible cultural heritage digitization platform.

Manchu traditional culture is the precious cultural heritage accumulated by Manchu working people in long-term practical activities. These cultural heritages are mainly scattered among the people. Therefore, to protect Manchu traditional culture, we should first collect the original materials scattered among the people, then convert them into a standardized digital format, then classify and sort these materials to make them become standardized data that can be intuitively felt and used, and finally store a variety of national cultural materials into the computer system through data sorting and classification, And realize resource sharing and utilization, and present the Manchu traditional culture to people through different data formats and transmission means, which can effectively strengthen the protection of traditional national culture.

\section{ACKNOWLEDGMENTS}

National Social Science Foundation of China Art Program, 21BG127, 2021.

Major projects of National Social Science Foundation of China, 19ZDA183,2019.

\section{REFERENCES}

[1]Junbo Dai, Construction of digital museum of Manchu intangible cultural heritage based onvirtual reality technology, Journal of Tonghua normal university,2021(2015-1):48-52.DOI:10.13877/j.cnk i.cn22-1284.2015.01.009

[2]Jian Xiao, The application of Manchu traditional cultural elements in architectural design, Art Education Research, 2016(5):170-170. DOI:10.3969/j.issn.1674-9286.2016.05.122.

[3]Xiaoqing Duan, The application of virtual reality to the protection of intangible cultural heritages, Studies in culture \& art, 2020,13(1):19-23. DOI:10.3969/j.issn.1674-3180.2020.01.004.

[4]Qibo Liu, JingfengTian, Probe into humanist environment protection of architecture in urban and rural under the concept of green architecture, Optimization of capital construction 2005,26(5):91-94.

[5]Tianming Yue, Weitao Zhao, Research on Manchu dwelling and rural landscape, journal of shandong forestry science and technology, 2008,38(6):102-104.DOI:10.3969/j.issn.1002-2724 .2008 .06 .038 . 